\title{
Supportive Parenting Buffers the Effects of Low Peer Acceptance on Children's Internalizing Problem Behaviors
}

\author{
Maryam Zarra-Nezhad ${ }^{1,2}$ (D) Ali Moazami-Goodarzi ${ }^{1,3} \cdot$ Kaisa Aunola $^{3}$. \\ Jari-Erik Nurmi ${ }^{3} \cdot$ Noona Kiuru ${ }^{3} \cdot$ Marja-Kristiina Lerkkanen $^{2}$
}

Published online: 15 July 2019

(C) The Author(s) 2019

\begin{abstract}
Background Children who are not accepted in their peer group are at risk of developing internalizing problem behaviors. It is possible, however, that supportive parenting can provide a buffer against the detrimental effects of low peer acceptance.

Objective This study examined maternal and paternal affection and psychological control as moderators of the association between children's peer acceptance during the critical transition to primary school and level and subsequent development of internalizing problem behaviors from first to sixth grade.

Method A total of 608 children ( 264 girls, 344 boys) were rated by their teachers on their internalizing problems in grades 1, 2, 3, 4 and 6. Children's peer acceptance was measured in the first grade using a sociometric nomination procedure. At the same time point, mothers $(n=432)$ and fathers $(n=281)$ completed questionnaires measuring their levels of affection and psychological control.

Results The results of latent growth curve modelling showed, first, that on average children's internalizing problems decreased over the school years. Second, peer acceptance was associated with the development of internalizing problems: the higher the peer acceptance, the bigger the decrease - and the lower the peer acceptance, the smaller the decrease-in the level of internalizing problems across time. However, high maternal affection provided a buffer against this impact of low peer acceptance. Among boys, low levels of maternal psychological control also provided a buffer against the effects of low peer acceptance. No significant results were found on the moderating role of fathers' parenting styles.

Conclusion Overall, the results suggested that mothers' emotionally sensitive and supporting caregiving may protect children from the harmful long-term effects of low peer acceptance.
\end{abstract}

Keywords Peer acceptance $\cdot$ Supportive parenting $\cdot$ Affection $\cdot$ Psychological control · Internalizing problems

Jari-Erik Nurmi is deceased on October 2017.

Maryam Zarra-Nezhad

maryam.zarra-nezhad@uef.fi

Extended author information available on the last page of the article 
Peer relationships play a key role in academic and adjustment outcomes of school-aged children (Kiuru et al. 2015; for a review, see also Parker et al. 2006), such as self-esteem, social and emotional skills, and mental health (for a review, see Parker et al. 2006; Shin et al. 2016). In turn, lack of peer acceptance in childhood has been shown to be a risk factor for developing various forms of internalizing problem behaviors, such as anxiety and depression (e.g., Healy and Sanders 2018; Hoglund and Chisholm 2014; Menting et al. 2015; Sakyi et al. 2015). Internalizing problem behaviors may have long-term consequences leading to interpersonal difficulties, social competence deficits, and academic problems (Barrett et al. 2005; see also Tennant et al. 2017). The impacts of low peer acceptance are not, however, necessarily the same for all: the consequences of low peer acceptance have been suggested to be weaker or non-existent for children who have supportive parents (Cohen and Wills 1985; Deci and Ryan 2000). Supportive parenting has, indeed, been shown to foster positive adjustment (e.g., Healy et al. 2015; Pettit et al. 1997), and buffer the negative impacts of problematic peer relationships in childhood (e.g., Bowes et al. 2010; Buckholdt et al. 2016; Hazel et al. 2014; Healy and Sanders 2018) and adolescence (e.g., Hazel et al. 2014; McDonald et al. 2010; Sentse and Laird 2010). The present study focusing on the critical transition to school aimed to examine to what extent supportive parenting can provide a buffer against the detrimental impact of the lack of peer acceptance at the beginning of school on development of internalizing problems during subsequent school years.

\section{Peer Acceptance and Internalizing Problem Behaviors}

During the period from middle to late childhood (6-12 years of age), the importance of peers is increased owing to the growth in children's interpersonal skills and the development of their peer relationships (for a review, see Parker et al. 2006). Peer relationships have been suggested to be an absolute necessity for healthy social and cognitive development, and socialization (Johnson 1980). According to Bukowski (2001), friendship provides a sense of self-value and personal validation, serves a protective function, facilitates learning and development of new skills, and shapes development through shared cultures (Maunder and Monks 2018). Peer status has been found to be relatively stable in elementary school years and to predict later social-emotional development and school adjustment (for a review, see Jiang and Cillessen 2005). Peer acceptance, which refers to being liked or accepted by the members of one's peer group (Bukowski and Hoza 1989), is an important developmental milestone in the first years of school. Peer acceptance has been linked, for example, to children's high psychological well-being, high academic performance, and successful adaptation in the school context (Hymel et al. 2011; Parker et al. 2006; Shin et al. 2016).

However, some children fail to build positive relationships with their peers. Peer relationship problems in childhood have been linked to a variety of developmental and psychological difficulties in childhood, adolescence, and adulthood (e.g., Arseneault 2017; Forbes et al. 2018; Sakyi et al. 2015; Shin et al. 2016). In particular, low peer acceptance has been recognized as an important antecedent of internalizing problem behaviors, i.e. symptoms of withdrawal, fearfulness, anxiety and depression (Healy and Sanders 2018; Ladd 2006; McDougall et al. 2001; Menting et al. 2015; Rubin et al. 2006; Sakyi et al. 2015). For example, a study on 6-12-year-old Australian children, followed over a 9-month period, found that supportive relationships with peers, in the form of peer acceptance, predicted 
changes in internalizing problems over time, with higher levels of peer acceptance predicting lower levels of later internalizing problems (Healy and Sanders 2018). A study on a sample with a mean age of 7-year-old (first grade) Korean children with 6- to 8-year follow-ups found that children's peer relationships had longitudinal effects on their mental health and adjustment. Children who had qualitative peer relation problems (less or no friends) were more likely to exhibit internalizing problems in adolescents (Shin et al. 2016). Further, a study which followed French children over 18 years (from the ages of 4-16 years to 22-35 years), found that individuals who had no friends at 4-16 years of age, were approximately twice more likely to experience internalizing symptoms compared to those who had at least one childhood friend (Sakyi et al. 2015). Furthermore, a study which followed children annually from the age of 6 (kindergarten) through to the age of 8 (second grade) in the Netherlands also found that emotional problems, such as internalizing symptoms, share poor peer acceptance as an underlying factor in their development (Menting et al. 2015).

The transition to first grade has been described as a critical period for children's development (e.g., Bossaert et al. 2011; Denham 2006; Ladd and Price 1987). Transition to school involves spending more time with peers, which also increases the various peerrelated demands such as forming new friendships and gaining acceptance in a new peer group (Coplan and Arbeau 2008). This transition can be both challenging and stressful for a child (Niesel and Griebel 2007), since children need to deal with increasing amounts of successes and failures not only in the academic area, but also in peer relations (Campbell and Stauffenberg 2007). The first grade, in particular, has significant prognostic value in terms of internalizing problems not only in the first grade, but also during late childhood (e.g., Bukowski et al. 2010; Ialongo et al. 1995; Shin et al. 2016) and adolescence (e.g., Grover et al. 2007; Shin et al. 2016). However, as far as we know less attention has been paid on possible cumulative and snowballing effects of peer problems, at the beginning of school career on subsequent development of internalizing problems (Bukowski et al. 2010; Shin et al. 2016).

\section{The Buffering Effect of Supportive Parenting}

There are some theoretical and empirical grounds suggesting that the negative impacts of problematic peer relationships in childhood and adolescence depends-at least to some extent-on the quality of the child-parent relationship. For example, the stress-buffering model (Cohen and Wills 1985) suggests that social support attenuates the relation between negative life events and the risk for internalizing problems. This model states that when faced with stressful life events, individuals with greater support are less likely to show internalizing symptoms than individuals with lower levels of support. According to the model (Cohen and Wills 1985), parents can act as buffers, protecting their children against the potentially pathogenic influence of stressful condition, such as low peer acceptance. When children are exposed to low peer acceptance, supportive parenting being evident, for example, in warmth, affection, monitoring, and positive engagement, may play an especially important role in their adjustment and behavioral outcomes. Supportive parenting may enhance a child's self-esteem, self-efficacy, and confidence by increasing the child's perception that he or she can cope effectively with low peer acceptance (Burton et al. 2004). In addition, supportive parents may help children in adapting problem-solving skills 
and coping strategies in the case of low peer acceptance, which then leads to lower internalizing problems (Hazel et al. 2014).

Previous cross-sectional studies have provided some support for the notion that supportive parenting may provide a buffer against the negative impacts of difficulties with peers on internalizing problems (e.g., Buckholdt et al. 2016; McDonald et al. 2010; McLachlan et al. 2010). For example, Buckholdt et al. (2016) found that positive maternal responses to a child's sadness and anger gave protection against the negative association of poor peer relations (e.g., low peer acceptance) with feelings of loneliness in 10-12-year-old children (grades 4-6). In a study on 14-year-old adolescents (ninth grade), McDonald et al. (2010) found that supportive relationships with mothers and fathers provided a buffer against the association between poor peer relationships and adolescents' internalizing difficulties. In another study, McLachlan et al. (2010) also reported that parental warmth played a protective role in the face of peer rejection, leading to a decrease in related anxious expectations among children and early adolescents (those aged 9 to 13 ).

There are also longitudinal studies demonstrating the buffering effect of supportive parenting against peer difficulties. For example, Patterson et al. (1989) found that high levels of maternal warmth before entering the first grade (at age 6), served as a protective factor against the psychosocial adjustment difficulties associated with peer rejection in the first grade. In another longitudinal study, Bowes et al. (2010) found that supportive parenting in terms of maternal warmth (measured when the child was 7 years old) buffered the negative consequences of peer victimization on children's subsequent internalizing problems at ages 10 and 12. Furthermore, Hazel et al. (2014) found that maternal and paternal supportive parenting (evidenced as close and positive relationships with children) buffered against the negative effects of peer problems (e.g., feeling pressure from friends or fighting with them) on the development of depressive symptoms in middle childhood (third grade, 7-9 years old; sixth grade, 10-12 years old) to adolescence (ninth grade, 13-16 years old). Finally, in a study by Healy and Sanders (2018) on 6-12-year-old children who were followed over a nine-month period, supportive parenting (in the form of warm parenting), was found to protect children against ongoing victimization and predict lower levels of internalizing problems over time. There are, however, also studies that have found no evidence for the buffering role of supportive parenting. For example, Sentse and Laird (2010) followed early adolescents (mean age 12.9 years) over a 1-year period and found that although maternal support (i.e., acceptance, warmth and support) provide a buffer against the association between friendship conflict and the development of depression in early adolescence, it did not protect against the association between peer rejection and internalizing problems. Similarly, in a study by Bilsky et al. (2013) on 8-14-year-old students, over three time points 6 months apart, no evidence was found for interaction between supportive parenting and peer relationship problems (in the form of peer victimization), on depressive symptoms.

In the present study, we focused on the buffering role of supportive parenting against the long-term impacts of low peer acceptance after the critical transition to primary school. More specifically, we examined whether the impact of low peer acceptance on the level and subsequent development of internalizing problem behaviors moderated by supportive parenting. Middle childhood is an important period for a child's development because it involves the transition to school, the development of independence, peer interaction and friendship, yet it continues to be strongly influenced by parents. Transition to school can be stressful and challenging for a child (Niesel and Griebel 2007), and as it can increase the risk of encountering failure in peer relations as well as academic areas (Campbell and Stauffenberg 2007), parental support at the start of the school year in particular can be assumed to play a highly significant role in a child 'subsequent adjustment outcomes. In 
the present study, supportive parenting was approached from two viewpoints. First, in line with previous studies on the topic we operationalized supportive parenting as one of the most often investigated aspects of parenting style dimensions, i.e. affection or warmth. Second, another aspect of supportive parenting, namely lack of psychological control, was also investigated as a possible moderator of peer relations. Psychological control refers to a style of parenting that is characterized by attempts to control the child's emotions and behavior through psychological means, such as withdrawal of love and induction of guilt (Barber 1996; Hart et al. 2003) and it can be seen to be an indicator of a lack of parental support (for a review, see McKee et al. 2008; see also Nanda et al. 2012; Zarra-Nezhad et al. 2014). Although previous research has mostly focused on the role of parental support in terms of warmth or positive affection as a buffer, i.e., the positive side of parenting, also lack of negative side of parenting can be considered to function as part of supportive parenting. For example, psychological control has been shown to be related to various forms of internalizing problems among children and adolescents (Barber 1996; Aunola and Nurmi 2005). Previous literature suggests that although parents show a high level of affection and are supportive, if they use psychological control in parenting, high affection and warmth may no longer provide protection problem behaviors (see, e.g., Aunola and Nurmi 2005; Aunola et al. 2018). Thus, when considering parents' buffering role against peer problems and other stressors, it might be important to examine not only the role of the positive side of parenting, but also focus on the lack of the negative side of parenting (i.e., psychological control).

Besides examining the moderating role of parenting against the impacts of low peer acceptance on the level and subsequent development of internalizing behaviors, gender differences in this phenomenon were investigated. Thus far, little is known about whether supportive parenting serves a similar or different role as a moderator of peer acceptance for boys and girls. It has been suggested that, from middle childhood on, girls generally place more emphasis on friendships (Maccoby 1998), become more easily depressed (e.g., Hale et al. 2005), and are more likely to suffer from negative interpersonal experiences such as low peer acceptance. However, boys have been reported to spend more time in large peer groups than girls (for a review, see Rose and Rudolph 2006), which may make them more likely to suffer from stressors at the group level (e.g., low peer acceptance) than girls (Lewin et al. 1999). It has also been suggested that boys who are rejected by their peers are more likely to feel anxious and expect future rejection than girls with a similar experience (London et al. 2007). However, to our knowledge, gender differences in terms of the role of supportive parenting as a buffer against low peer acceptance have not yet been examined.

\section{Current Study and Hypotheses}

Three research objectives were addressed in this study. (1) To what extent does peer acceptance at first grade predict a child's initial level and subsequent development of internalizing problem behaviors during their primary school years (i.e., across grades $1,2,3,4$, and 6)? Based on previous literature, we expected that experiences with peers at the beginning of a child's school career (first grade) would not only be associated with the initial level of internalizing problems, but also predict the subsequent developmental trend of these (e.g., Bukowski et al. 2010; Shin et al. 2016). More specifically, low peer acceptance in the first grade was expected to be positively associated with both the level and the developmental trend (i.e., either larger increase or smaller 
decrease across time depending on the direction of the trend) of internalizing problems across grades 1 to 6 . (2) To what extent is the impact of peer acceptance on the level and developmental trend of a child's internalizing problem behaviors moderated by affection and psychological control exhibited by her/his mother and father? Based on the stress-buffering model (Cohen and Wills 1985), our assumption was that supportive parenting in terms of high parental affection and low psychological control in first grade would provide a buffer against the impacts of low peer acceptance on children's subsequent internalizing problems across grades 1 to 6 . Since childrearing approaches have been reported to be relatively stable in early childhood (e.g., Roberts et al. 1984) and over longer periods of time (i.e., from aged 7-8 years until children reach 15-26years of old; McNally et al. 1991), parenting styles in first grade was expected to be predictive across primary school years. (3) To what extent are the buffering effects of high parental affection and low psychological control different for boys and girls? Because of the lack of previous research concerning the moderating role of the child's gender, no hypotheses were set.

\section{Method}

\section{Participants and Procedure}

The present study is part of a longitudinal study (Lerkkanen et al. 2006-2016) that followed a larger sample of 1880 children from preschool up to ninth grade in different regions of Finland. In the present sub-study, a target sample of 608 children (264 girls, 344 boys) was drawn from this larger sample in order to decrease the data collection demands placed on teachers. The target sample was determined by randomly selecting a small number of students from each first-grade classroom. Typically, three children were selected from each classroom $(M=2.53, S D=0.84)$, but this number varied from one to six depending on the size of the class.

Comparisons between the random target sample and the larger sample revealed no differences between the samples in terms of the type of family and parental level of education. The vast majority of children in the target sample (76\%) came from nuclear families, $12 \%$ were from single-parent families, and $12 \%$ from blended families. A total of $25 \%$ of the children's mothers had a master's degree or higher, $37 \%$ had a bachelor's or vocational college degree, $31 \%$ had completed secondary education, and $7 \%$ had no qualification beyond secondary school. A total of $22.80 \%$ of the children's fathers had a master's degree or higher, 33\% had a bachelor's or vocational college degree, $34.70 \%$ had completed secondary education, and $9.50 \%$ had no qualification beyond secondary school. The sample was fairly representative of the level of education among the general population in Finland (Statistics Finland 2007).

Children's levels of internalizing problems were rated by their teachers in grade 1 (April 2008), grade 2 (April 2009), grade 3 (April 2010), grade 4 (April 2011), and grade 6 (April 2013). Mothers and fathers were asked to complete questionnaires at home concerning their parenting styles, independently and without conferring, when their children were in the first grade. Information on parenting styles was available to 432 of the mothers $(71.05 \%)$ and 281 of the fathers $(46.21 \%)$. 


\section{Measures}

\section{Peer Acceptance}

Students' peer acceptance was measured in the first grade using a sociometric nomination procedure. Accepted children were those who were liked or preferred by peers or were most often named as a friend. Students were asked to circle (from a list of all the students in the class) the names of those with whom they most liked to spend time with during breaks (see Kiuru et al. 2015). The number of permitted nominations varied by class size; if the number of students in the class was 12 or greater, then three nominations were permitted. If the number of students in the class was $8-11$, two nominations were permitted. If the number of students in the class was fewer than eight, only one nomination was permitted. Peer acceptance represents the number of nominations each student received, standardized by class size. Sociometric nominations have been shown to provide valid, stable, and reliable assessments of peer acceptance during early childhood (Terry 2000).

\section{Internalizing Problem Behaviors}

During grades $1,2,3,4$, and 6, teachers were asked to rate each child on a 3-point rating scale $(1=$ does not apply, $2=$ applies partly, $3=$ certainly applies $)$ using the Strengths and Difficulties Questionnaire (SDQ, for 4-17 years old; Goodman 1997). The Emotional Symptoms subscale (five items; e.g., "Is often unhappy, down-hearted or fearful") of SDQ was used as an indicator of internalizing problem behaviors. Mean scores for this subscale were calculated at each of the time points. The Cronbach's $\alpha$ of internalizing problems at different time points ranged from 0.74 to 0.76 .

\section{Parental Affection and Psychological Control}

Mothers' and fathers' levels of affection and psychological control were measured using a revised Finnish version (Aunola and Nurmi 2004) of Block's Child-Rearing Practices Report (CRPR; Roberts et al. 1984). Parents were asked to rate 14 items measuring affection and psychological control on a 5-point scale $(1=$ does not fit me at all; $5=$ fits me very well). The affection dimension (10 items, e.g., "I often show my child that I love him/her") measured parental warmth and responsiveness. The psychological control dimension (four items, e.g., "I believe my child should be aware of how much I have done for him/her") measured parental attitudes stirring up guilt on the part of the child and expressing disappointment. Cronbach's $\alpha$ regarding these dimensions was, respectively, 0.83 and 0.71 for mothers and 0.83 and 0.74 for fathers.

Attrition analyses were conducted to determine if children whose mothers did $(n=432$, $71 \%)$ and did not $(n=176,29 \%)$ return the questionnaires differed in the study variables. The results of independent samples t-tests showed that there were no significant differences between the two groups in peer acceptance $(t(588)=0.98 p=.32)$. Results further showed no significant differences between the two groups in internalizing problems except at T2 ( $t$ $(482)=2.52, p=.01)$ which internalizing problems were higher in children whose mothers did not return the questionnaire. Next, attrition analyses were conducted to determine if children whose fathers did $(n=281,46 \%)$ and did not $(n=327,54 \%)$ return the questionnaires differed in the study variables. The results of independent samples $t$ tests showed that there were no significant differences between the two groups in peer acceptance $(t$ 
$(588)=-1.27, p=.20)$. Results furthermore showed no significant differences between the two groups in internalizing problems except at T3 $(t(451)=3.12, p=.001)$ which internalizing problems were higher in children whose fathers did not return the questionnaire.

\section{Analysis Strategy}

In order to examine the impact of peer acceptance on the development of children's internalizing problems and to determine the extent to which these associations vary depending on parental affection and psychological control, we employed latent growth curve modelling (LGCM) in the data analysis. In these models, the latent intercept variable representing the initial level of internalizing problems at first grade was estimated by setting factor loadings of observed internalizing problem variables at different time points to be 1 . A latent slope variable representing a linear trend in internalizing problems was estimated by setting factor loadings of observed internalizing problem variables at T1-T5 to be 0 , $1,2,3$, and 5, respectively. Setting the first slope factor loading at $\mathrm{T} 1$ at zero meant that the intercept described the level of internalizing problems at the onset of the study. The residual variances of the observed variables were freely estimated. Next, we built conditional latent growth models by incorporating peer acceptance, parenting variables (separate models including mothers' and fathers' variables), and their interaction terms as predictors of inter-individual differences in the level and developmental trend of internalizing problems. Finally, we conducted multi-group analyses by dividing the sample into two groups, girls and boys, and then investigated whether the effects of predictors on the level of and changes in internalizing problems were different in these two groups.

To examine the interactions between parenting variables and peer acceptance in terms of children's internalizing problems in greater detail, we used the Johnson-Neyman technique (Preacher et al. 2006). This procedure produces the precise regions of the continuum of parenting variable for which the regression slope of peer acceptance on the developmental trend (i.e., slope) of internalizing problems $(\mathrm{X} \rightarrow \mathrm{Y})$ is estimated to be significantly different from zero. In these analyses, the regions of significance represent the range of moderator variable $\mathrm{z}$ (i.e., particular parenting variable), within which the association of independent variable $x$ (i.e., peer acceptance) with dependent variable y (i.e., slope of internalizing problems) is significantly different from zero at the chosen $\alpha$-level. As a result of the method, two values describing the upper and lower boundaries of the region of significance are calculated and plotted. The effect of peer acceptance on the slope of internalizing problems is significant at values of the parenting variable that are less than the lower boundary and greater than the upper boundary, while the effect of peer acceptance is nonsignificant at values of the parenting variable falling within the region.

The fit indices utilized included the Comparative Fit Index (CFI), the Tucker-Lewis Index (TLI), and the Root Mean Square Error of Approximation (RMSEA). For the CFI and the TLI, values between 0.90 and 1.00 indicate a good fit between the model and the data. An RMSEA value of 0.05 or less indicates a good fit, while values up to 0.08 indicate a reasonable error of approximation. The fits of the nested models were compared by examining the significant changes in the Chi square values and degrees of freedom. All the analyses were carried out using the Mplus statistical package (Version 7.0; L.K. Muthén and Muthén 1998-2015). The results of Little's MCAR test for the study variables revealed that the data was completely missing at random: $\left(\chi^{2}(398)=431.62, p=.12\right)$. The parameters of the models were estimated using the full information maximum likelihood (FIML) estimation with standard errors that are robust to non-normality (MLR estimator) (Muthén 
and Muthén 1998-2010). This method allowed the use of all observations in the data set to estimate the parameters in the models without the imputation of missing values. The means, standard deviations, internal consistencies, and correlations for the observed variables are presented in Table 1.

\section{Results}

\section{Developmental Trend of Children's Internalizing Problem Behaviors}

The results suggested a good model fit for the linear latent growth curve model for internalizing problems $\left[\chi^{2}(d f=10, N=565)=31.59, p<.001 ; \operatorname{RMSEA}=0.06 ; \mathrm{CFI}=0.95\right.$; $\mathrm{TLI}=0.95$ ]. The estimated mean values of the intercept and slope were 1.32 ( $S E=0.02$, $p<.001)$ and $-0.02(S E=0.01, p=.05)$, respectively, suggesting that, on average, internalizing problems decreased statistically significantly across the school years. Also, the variance of intercept (variance $=0.10, S E=0.01, p<.001$ ) and slope (variance $=0.02$, $S E=0.00, p<.001)$ were statistically significant, indicating individual differences in internalizing problems when children first entered school, as well as in the developmental trend of internalizing problems.

\section{The Role of Supportive Parenting and Peer Acceptance}

Next, conditional latent growth models were constructed by adding mothers'/fathers' parenting variables, peer acceptance, and their interaction terms as predictors of the intercept and slope of internalizing problems for the LGCM. Separate models were carried out for each parenting variable. To test our hypothesis concerning the differential effects of parenting and peer acceptance and their interaction with children's internalizing problems depending on the child's gender, we started the analysis by conducted multiple-group LGCMs. By applying this method, we compared freely estimated models (all predictive paths estimated separately among boys and girls) to constrained models (all predictive paths constrained to be equal across boys' and girls' groups) via a Chi square difference test to reveal whether the relationships among parenting variables, separately, peer acceptance, and the interaction terms of parenting variables and peer acceptance, on children's initial level and developmental trend of internalizing problems would vary between the boys and girls in our sample. If no gender differences were evident, final analyses were carried out for the whole sample.

\section{Parental Affection}

The results showed that in the case of mothers' affection, the freely estimated model was not statistically better than the constrained model $\left(\Delta \chi^{2}(6)=0.68, p=.99\right)$, suggesting that the associations of maternal affection, peer acceptance, and their interactions with children's internalizing problems were similar for boys and girls. Consequently, a conditional growth model was applied to the whole sample. The results of the models including mothers' affection are shown in Table 2. The model for mothers' affection and children's peer acceptance and internalizing problems indicated an acceptable fit (Table 2). First, the results showed that mothers' affection was not related to the initial level or developmental trend of internalizing problems in children. Peer acceptance was negatively related to the 


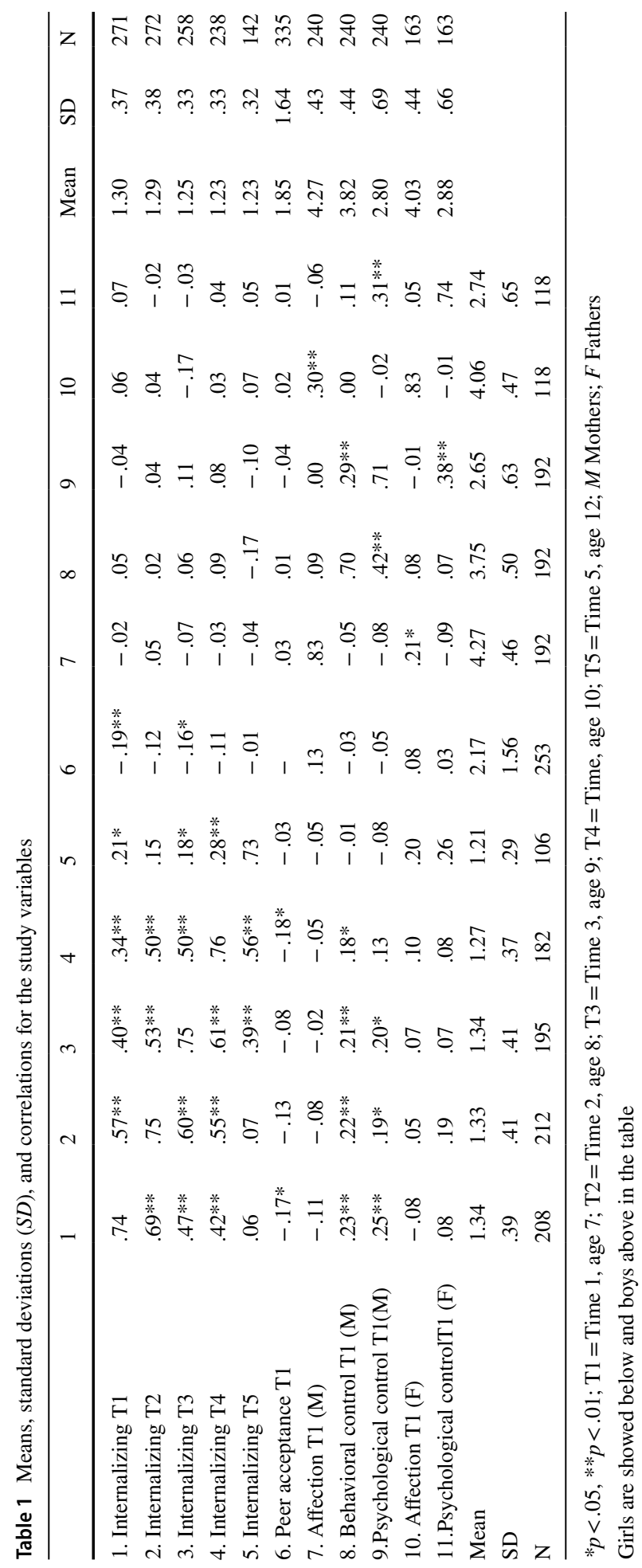


Table 2 Main and interaction effects of parenting styles and peer acceptance predicting children's internalizing problems

Internalizing problems

\begin{tabular}{|c|c|c|c|c|c|c|c|c|c|}
\hline & \multicolumn{2}{|l|}{ Intercept } & \multicolumn{2}{|l|}{ Slope } & \multirow[t]{2}{*}{$\chi^{2}(d f)$} & \multirow[t]{2}{*}{ CFI } & \multirow[t]{2}{*}{ TLI } & \multirow[t]{2}{*}{ RMSEA } & \multirow[t]{2}{*}{ SRMR } \\
\hline & $\begin{array}{l}\text { Estimate } \\
(\mathrm{SE})\end{array}$ & $P$ value & $\begin{array}{l}\text { Estimate } \\
\text { (SE) }\end{array}$ & $P$ value & & & & & \\
\hline \multicolumn{10}{|l|}{ Mothers } \\
\hline A. Affection & $-.01(.06)$ & .84 & $-.02(.06)$ & .77 & $40.40(19)$ & .96 & .95 & .04 & .08 \\
\hline $\begin{array}{l}\text { B. Peer } \\
\text { acceptance }\end{array}$ & $-.26(.05)$ & .00 & $.02(.05)$ & .66 & & & & & \\
\hline$A \times B$ & $.02(.07)$ & .81 & $.12(.05)$ & .02 & & & & & \\
\hline $\begin{array}{l}\text { A. Psycho- } \\
\text { logical } \\
\text { control }\end{array}$ & $.14(.06)$ & .03 & $.00(.07)$ & .95 & 40.58 (16) & .95 & .94 & .05 & .09 \\
\hline $\begin{array}{l}\text { B. Peer } \\
\text { acceptance }\end{array}$ & $-.26(.05)$ & .00 & $.03(.05)$ & .57 & & & & & \\
\hline$A \times B$ & $-.02(.06)$ & .72 & $-.01(.05)$ & .81 & & & & & \\
\hline \multicolumn{10}{|l|}{ Fathers } \\
\hline A. Affection & $-.02(.07)$ & .78 & $.08(.08)$ & .34 & 39.54 (16) & .95 & .94 & .05 & .09 \\
\hline $\begin{array}{l}\text { B. Peer } \\
\text { acceptance }\end{array}$ & $-.26(.05)$ & .00 & $.03(.05)$ & .62 & & & & & \\
\hline $\mathrm{A} \times \mathrm{B}$ & $.09(.07)$ & .19 & $.05(.07)$ & .40 & & & & & \\
\hline $\begin{array}{l}\text { A. Psycho- } \\
\text { logical } \\
\text { control }\end{array}$ & $.01(.08)$ & .90 & $.14(.07)$ & .05 & $38.23(16)$ & .96 & .95 & .05 & .09 \\
\hline $\begin{array}{l}\text { B. Peer } \\
\text { acceptance }\end{array}$ & $-.25(.05)$ & .00 & $.02(.05)$ & .65 & & & & & \\
\hline$A \times B$ & $-.01(.08)$ & .84 & $-.03(0.8)$ & .68 & & & & & \\
\hline
\end{tabular}

level of internalizing problems $(\beta=-0.26, p<.001)$ but not to the developmental trend of it: the lower the level of peer acceptance, the higher the level of internalizing problems in children. The results showed, however, that the interaction term between peer acceptance and maternal affection was statistically significant for the trend $(\beta=0.12, p=.04)$ of internalizing problems. In other words, the strength of the relationship between peer acceptance and the development of internalizing problems varied as a function of maternal affection. To interpret this interaction further, the Johnson-Neyman technique was utilized. The results are shown in Fig. 1.

As shown in Fig. 1, the effect of peer acceptance on the developmental trend of internalizing problems was statistically significant and negative only when maternal affection was low (values below - 1.2 SD): the higher the peer acceptance in first grade, the greater the decrease in internalizing problems across grades 1 to 6 - and the lower the peer acceptance in first grade, the smaller the decrease in internalizing problems from grade 1 to 6 - among children whose mothers showed low levels of affection in first grade. However, when the mother showed moderate or high levels of affection, peer acceptance showed no effect on the trend of internalizing problems.

Next, a model including fathers' affection was created. The results showed that for paternal affection the freely estimated model was not statistically better than the constrained 


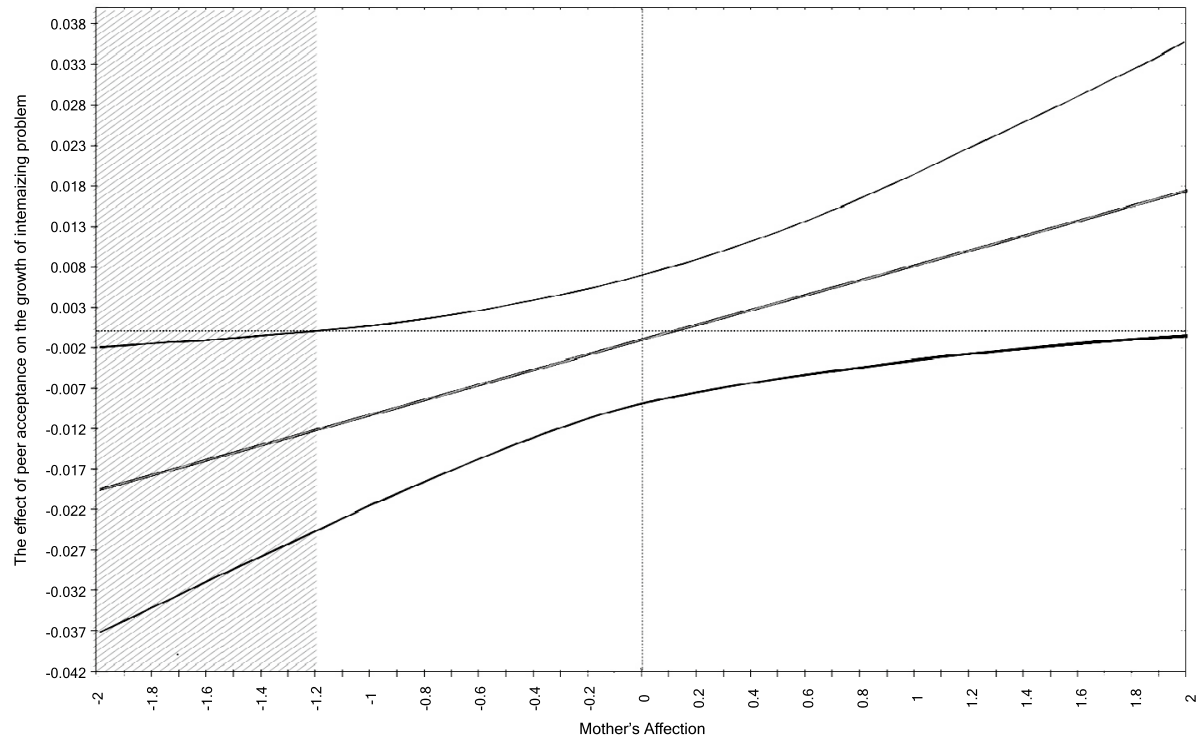

Fig. 1 The effect of low peer acceptance on the developmental trend of children's internalizing problem behaviors as a function of maternal affection. The X-axis depicts a continuous range of maternal affection (moderator variable) values. The Y-axis depicts a continuous range of values for the adjusted effect of peer acceptance on the trend of internalizing problem behaviors. The straight plot line represents values of the adjusted effect that correspond to the full range of all continuous values of maternal affection requested (i.e., $-2 S D$ to $+2 S D$ ). The curved lines above and below the plot line represent $95 \%$ confidence bands around the adjusted effect of peer acceptance on the trend of internalizing problems. Gray shaded areas denote regions (the maternal affection values below $-1.3 S D$ ) where the two lines statistically significantly differ

models $\left(\Delta \chi^{2}(6)=5.74, p=.55\right)$, suggesting that the associations of fathers' affection, peer acceptance and their interactions with children's internalizing problems was similar for boys and girls. Consequently, conditional growth model was conducted to the whole sample. The results for paternal affection and children's peer acceptance and internalizing problems indicated an acceptable fit (Table 2). The results showed that paternal affection in first grade was not related to the initial level or developmental trend of internalizing problems in children across grades 1 to 6 . No statistically significant interaction effects between peer acceptance and paternal affection in first grade were found either.

\section{Parental Psychological Control}

The model for maternal psychological control showed that the freely estimated model $\left(\chi^{2}\right.$ $(d f=39, N=586)=62.12, p<.001 ; \mathrm{RMSEA}=0.04 ; \mathrm{CFI}=0.96$; TLI $=0.95)$ fitted the data better than the constrained model $\left(\chi^{2}(d f=45, N=586)=74.34, p<.001\right.$; RMSEA $=0.04$; $\left.\mathrm{CFI}=0.95 ; \mathrm{TLI}=0.94 ; \Delta \chi^{2}(6)=12.22, p=.04\right)$, suggesting that the estimated paths are different among boys and girls. The results of the model estimating paths separately among boys and girls showed two differences between boys and girls. First, the results showed that mothers' psychological control was related to the initial level of internalizing problems only among girls: the higher the maternal psychological control in first grade, the higher the level of internalizing problems at first grade among girls $(\beta=0.27, p=.001)$ but 


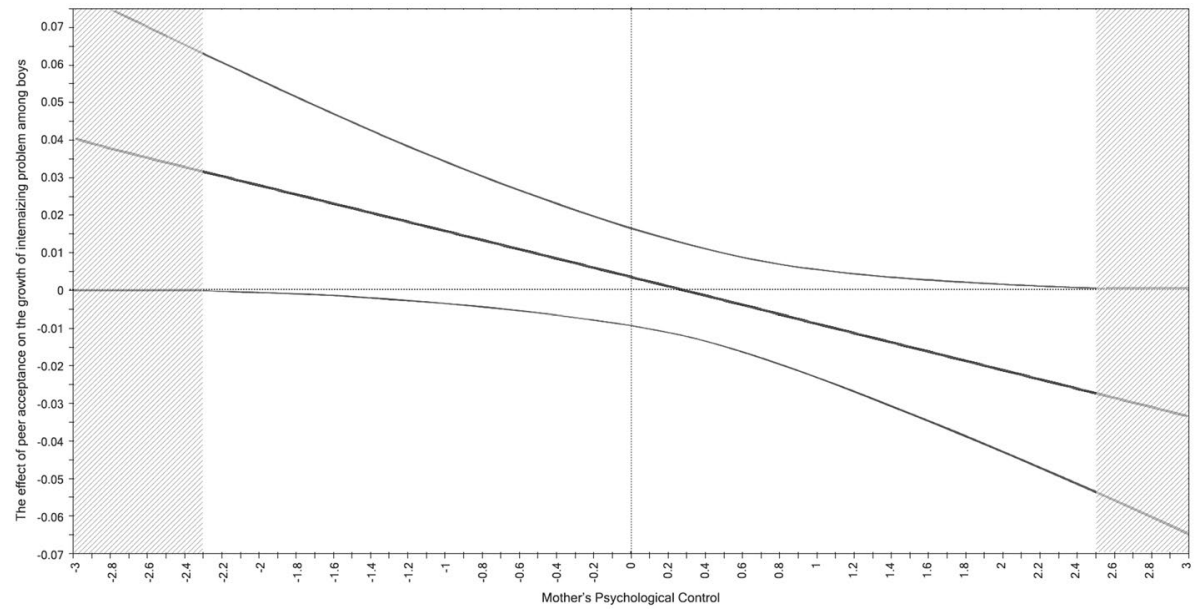

Fig. 2 The effect of low peer acceptance on the developmental trend of boys' internalizing problem behaviors as a function of mothers' psychological control. The $\mathrm{X}$-axis depicts a continuous range of maternal psychological control (moderator variable) values. The Y-axis depicts a continuous range of values for the adjusted effect of peer acceptance on the trend of internalizing problem behaviors. The straight plot line represents values of the adjusted effect that correspond to the full range of all continuous values of maternal psychological control requested (i.e., $-2 S D$ to $+2 S D$ ). The curved lines above and below the plot line represent $95 \%$ confidence bands around the adjusted effect of peer acceptance on the trend of internalizing problems. Gray shaded areas denote regions (the psychological control values above $+2.5 S D$ and below $-2.3 S D$ ) where the two lines statistically significantly differ

not among boys $(\beta=0.03, p=.71)$. Comparing the freely estimated model with the model constraining only this one path (path from maternal psychological control to the level of internalizing problem behaviors) to be same for boys and girls, confirmed statistically significant difference between boys and girls $\left(\Delta \chi^{2}(1)=3.96, p=.04\right)$.

Second, the interaction between peer acceptance and mothers' psychological control on the developmental trend of internalizing problems was statistically significant only among boys (estimate for boys: $\beta=-0.21, p=.04$ estimate for girls: $\beta=0.11, p=.05$ ). Comparing the freely estimated model with the model constraining only this one path (path from the interaction term to the developmental trend of internalizing problem behaviors) to be same for boys and girls, confirmed statistically significant difference between boys and girls $\left(\Delta \chi^{2}\right.$ $(5)=11.45, p=.04$ ). The results gained from using the Johnson-Neyman technique (Fig. 2) showed that when mothers showed a high level of psychological control (over $+2.5 S D$ ), the effect of peer acceptance on the trend of internalizing problems among boys was negative: the lower the peer acceptance in first grade, the less the decrease in internalizing problems among boys across grades 1 to 6 . When maternal psychological control was low (below $-2.3 S D$ ), the effect of peer acceptance on the trend of internalizing problems among boys was reversed: the lower the peer acceptance in first grade, the greater the decrease in internalizing problems across grade 1 to 6 among boys.

When a similar model including psychological control was tested for fathers, the results showed that the freely estimated model was not statistically better than the constrained model $\left(\Delta \chi^{2}(6)=3.60, p=.71\right)$, suggesting that the associations of fathers' psychological control, peer acceptance and their interactions with children's internalizing problems was similar for boys and girls. Consequently, the model for the whole sample was estimated. The fit of the model was good (see Table 2). The results showed that fathers' psychological 
control was positively related to the developmental trend of children's internalizing problems $(\beta=0.14, p=.05)$ but not to the level: the lower the level of paternal psychological control in first grade, the greater the decrease in internalizing problems from grades 1 to 6; and the higher the level of paternal psychological control in first grade, the smaller the decrease in internalizing problems from grades 1 to 6 . No statistically significant interaction effects between paternal psychological control and peer acceptance were found.

\section{Discussion}

The principal aim of this study was to obtain a deeper understanding of the role of supportive parenting in terms of buffering the negative impacts of low peer acceptance on children's internalizing problem behaviors from grades 1 to 6 . We investigated whether peer acceptance at first grade after the critical transition to school predicts internalizing problems in subsequent primary school years. We also explored the moderating role of parental affection and psychological control on the relation between a child's peer acceptance and internalizing problems, and possible gender differences in this.

\section{Association Between Peer Acceptance and Internalizing Problem Behaviors}

We hypothesized that low peer acceptance in the first grade is not only associated with a higher level of internalizing problems, but also positively predicts the developmental trend of these problems being evident either as greater increase of internalizing problems across time, or less decrease in these, depending on the general trend of internalizing problems. This hypothesis was partly supported. Low peer acceptance was associated with initial higher levels (but not with subsequent change) of internalizing problems at the beginning of primary school. This result was in line with previous studies showing that low peer acceptance is associated with various kinds of internalizing problems (e.g., Gifford-Smith et al. 2005; Klima and Repetti 2008; Ladd 2006; Menting et al. 2015). According to selfdetermination theory (Deci and Ryan 2000), relatedness (i.e., a feeling of belonging and being significant in the eyes of others) is a basic psychological need that is essential for healthy development and well-being. For example, lack of peer acceptance can negatively affect the children's self-perception by making them believe that they are not worthy of being accepted (Ladd and Troop-Gordon 2003). Low peer acceptance may also undermine children's sense of relatedness, which contributes to increased feelings of loneliness and other internalizing symptoms such as anxiety, depression and withdrawal (Klima and Repetti 2008; Ladd 2006; Parker et al. 2006). Because at the level of the whole sample low peer acceptance was associated only with the initial level, and not with the developmental trend of internalizing problem behaviors, this association could also be interpreted the other way around. It is possible that internalizing problem behaviors impact on peer acceptance rather than vice versa. For example, if a child has a high level of internalizing problems, it is possible that she/he is also more prone to withdraw from the peer group, which then affects how peers interact with him/her. Although low peer acceptance did not predict subsequent development of internalizing problems at the level of the whole sample, our results nevertheless demonstrated that the association of lack of peer acceptance on the developmental trend of internalizing problem behaviors was dependent on the level of maternal supportive parenting. 


\section{The Moderating Role of Supportive Parenting}

We hypothesized that a high parental affection and low level of psychological control would moderate the relation between peer acceptance and internalizing problems by buffering the negative effect of low peer acceptance on the level and developmental trend of a child's internalizing problems. The results concerning maternal affection supported our hypotheses by demonstrating that maternal affection protected children against the detrimental impacts of low peer acceptance: low peer acceptance predicted less positive developmental outcomes only when the level of maternal affection was low. When mothers exhibited moderate or high maternal affection, low peer acceptance showed no effects on the developmental trend of internalizing problems. This result is consistent with the stressbuffering model (Cohen and Wills 1985), and previous findings suggesting that parental affection and support can act as a buffer against the negative impacts of poor peer relationships on internalizing problems over time (Bowes et al. 2010; Hazel et al. 2014; Healy and Sanders 2018); Patterson et al. 1989). This result was, however, inconsistent with the findings of Bilsky et al. (2013) and Sentse and Laird (2010) that reported maternal support did not moderate the negative impact of peer relationship difficulties on internalizing problems. The discrepant results may be due to the fact that these two previous studies focused on adolescents, whereas the present study focused on primary school children. As children begin their transition into adolescence, supportive parenting in terms of parental warmth and affection may decrease (e.g., McGue et al. 2005). Thus, it is possible that parents are less influential as children age (Collins et al. 1997; see also, Hazel et al. 2014).

The results of the present study can be interpreted in the light of the stress-buffering model (Cohen and Wills 1985) according to which social support, or positive relationships with others (e.g., parents), protects against the potentially pathogenic influence of stressful life situation (such as poor peer relationships). According to this model, supportive parents help their children in adapting problem-solving skills and coping strategies and enhance their confidence, self-efficacy, and self-esteem, which may then lead to lower internalizing problems in the case of low peer acceptance. A second possible explanation for our results is that since warm and positive parenting is characterized by better parent-child communication and more social support (Ranson and Urichuk 2008), this kind of mothering may provide the emotional support that low peer-accepted children need. For example, children who have warm and positive mothers may be more willing to disclose and share their feelings of rejection, which makes mothers more aware of what is going on in their young children's classrooms. Thus, warm and engaged mothers may invest more time and effort in helping their first-grade children get involved in extracurricular activities where they are able to find alternative opportunities to gain social skills outside of school. Third, it is possible that warm and supporting mothers are more attuned to their children's difficulties in fitting into classroom social dynamics and do a better job of helping children cultivate personal strengths that do not depend so heavily on social feedback from peers. These mothers may be more likely to support and instruct their children in the use of coping strategies that provide them with the tools they need to deal with the pressures of negative feedback from peers and provide children with more positive and adaptive appraisals of stress (Hazel et al. 2014). This might then protect children from internalizing symptoms and provides them with alternative ways to build their self-esteem. It is nevertheless notable that we did not empirically test the above-discussed possible mechanisms underlying the buffering effect of high maternal affect. Future studies are needed to empirically test these alternative explanations. 
Although our results showed that maternal affection buffered against the impacts of low peer acceptance on the developmental trend of internalizing problems, no such result was found concerning fathers' affection. Thus, the findings suggest that it is particularly maternal rather than paternal affection that has buffering effect on children's subsequent development of internalizing symptoms over the school years. This result is understandable when taking into account that mothers are often the primary caretakers, taking primary responsibility for children in families, and spend more time with their children (Lamb and Oppenheim 1989; Renk et al. 2003). Thus, their parenting styles may naturally play a more important role in a child's emotional development than the father's parenting does (ZarraNezhad et al. 2015). Alternatively, perhaps children tend to be more open to maternal than paternal influence (Aunola and Nurmi 2005) because interactions between mother and child are typically characterized by greater responsiveness, warmth and intimate exchanges than interactions between father and child (Collins and Russell 1991). However, because of the relatively small sample size of fathers in our sample, further research is needed to detect the buffering role of fathers' affection.

The results concerning the moderating role of parental psychological control also partly supported our hypothesis in the case of mothers: when mothers showed a high level of psychological control, low peer acceptance was associated with relatively higher subsequent levels of internalizing problems among boys. On the contrary, when maternal psychological control was low, a lack of peer acceptance among boys was related to decreased rather than increased internalizing problems. For girls, this kind of result was not found suggesting some gender differences in the impact of low peer acceptance on internalizing problems across the school years depending on the level of maternal psychological control. The result for boys is consistent with the stress-buffering model (Cohen and Wills 1985), and our assumption, suggesting that low maternal psychological control as one form of supportive parenting can protect against the negative impacts of low peer acceptance. When interpreting the results in the light of the stress-buffering model (Cohen and Wills 1985), non-supportive mothering in terms of psychological control (i.e. controlling the child's emotions and behavior through psychological means) might be assumed to decrease the child's confidence, self-efficacy, and self-esteem in the face of stressful life situation such as low peer acceptance, and, by this way, foster rather than prevent internalizing problems.

Another possible explanation for this result is that high levels of maternal psychological control ignore the child's fundamental need for autonomy (Soenens and Vansteenkiste 2010), consequently intensifying children's symptoms of internalizing problems (Barber and Xia 2013; El-Sheikh et al. 2010). It is also possible that boys whose mothers use psychological control develop a negative sense of self as a consequence of maternal emotional unavailability, which then leads them to adopt maladaptive coping strategies in peer relationships. They may, for example, feel increased pressure to win social acceptance and get attention from peers, and may lack effective coping skills to deal with low levels of acceptance from peers. This then may put them at a higher risk of internalizing symptoms, such as low self-esteem and depression (for a review, see Soenens and Vansteenkiste 2010). On the other hand, boys whose mothers show very low levels of psychological control may help their sons to develop a stable, secure and positive sense of self, which then helps them to cope adaptively in the case of peer rejection. Although the combined effect of maternal psychological control and peer acceptance was only evident among boys, the main effect of mothers' psychological control on the level of internalizing problems was found only among girls. Overall, these results suggest that although girls may be more prone to the negative impacts of maternal psychological control in general, boys showing low peer acceptance, in particular, may benefit from supportive mothering in terms of low 
psychological control. One explanation for this pattern of results is that because in middle childhood boys spend more time in large peer groups than girls (for a review, see Rose and Rudolph 2006), they suffer more by being rejected by their peers than girls (London et al. 2007) and, thus, also benefit more from compensating supportive mothering.

Another possible mechanism that might explain this result is that in middle childhood boys and girls use different coping strategies when dealing with peer difficulties (Visconti and Troop-Gordon 2010). For example, girls respond in a more prosocial manner to hypothetical peer conflict situations than boys in middle childhood (for a review, see Rose and Rudolph 2006). Similarly, in case of peer rejection, girls are more likely to use strategies to further the discussion of emotions within a situation, walk away from the conflict, or seek support if necessary, whereas boys engage less in prosocial behaviors, i.e., they show less control over negative emotions and less effective coping strategies (Fabes and Eisenberg 1992; Smith et al. 2001), which may put them at a higher risk of behavioral problems. Consequently, boys may benefit more from maternal supportive parenting, which provides them with an alternative source of emotional support and helps them to develop adaptive and effective coping skills to deal with experienced low levels of peer acceptance and decrease the risk of internalizing problems. Future studies on gender differences are needed, however, to provide support for these kinds of conclusions.

As was the finding in the case of parental affection, our results further revealed that low paternal psychological control did not protect children against the detrimental impacts of low peer acceptance either. Overall, the results suggest that mothers and fathers may play a different role when it comes to buffering against low peer acceptance. Although both mothers' and fathers' psychological control was found to be associated with high levels of internalizing problems among children, it was maternal rather than paternal affection and psychological control that showed a buffering effect on children's subsequent development of internalizing symptoms over the school years.

\section{Limitations}

This study had some limitations that must be taken into account. First, peer acceptance and parenting styles was measured only once, at the beginning of the study. Peer status and parenting may, however, change over the school years. Consequently, further studies are needed to examine the developmental dynamics between peer acceptance and children's internalizing problems as well as the buffering role of parenting in this development. Second, only parents' self-report measures were used for measuring parenting styles and these self-reports may be impacted by social desirability. Third, using a teacher report for internalizing problem behaviors may limit assessment of this kind of behaviors in one context only (i.e., school). On the other hand, it is also a strength of our study that we were able to show rater-independent associations between the investigated constructs, that is, parenting styles (reported by parents), peer acceptance (rated by peers) and internalizing problems (rated by teachers). When common method bias could not affect our results, our longitudinal findings may be more robust. Fourth, the fathers' sample $(n=281)$ was relatively small compared to the mothers' sample $(n=432)$, which may have reduced the statistical power of some of the analyses concerning fathers. Fifth, although it is possible that parental affection and psychological control have also interactive effect on children's developmental outcomes (e.g., Aunola and Nurmi 2004; Aunola et al. 2018), in the present study these effects were not empirically tested due to the relatively small sample and other 
moderator variables. In further studies with larger sample sizes the four-way interaction effects of Affection $\times$ Psychological control $\times$ Gender $\times$ Peer acceptance should also be tested in order to get more deeper and broader insight on the complex interplay of parenting and peer acceptance when predicting children's internalizing problems. Finally, all the results were obtained on Finnish children and further research in other regions of the world is needed in order to generalize the findings.

\section{Conclusions}

Overall, the results of this study suggest that low peer acceptance at the very beginning of primary school is associated with higher levels of internalizing problem behaviors from first grade to sixth grade. The first grade can be challenging and stressful for a child, because after the transition to school, peer relationships are largely reformed, and children face a greater risk of encountering failure in peer relationships. Peer status has been found to be relatively stable in the elementary school years and to predict later social and emotional development, and school adjustment (for a review, see Jiang and Cillessen 2005). Therefore, low peer acceptance in this period can have a long-term negative impact on the child's further social and emotional development, manifested in the form of increased internalizing problems, for example. However, our results showed that mothers' supportive parenting style, characterized by high levels of affection and sensitive caregiving, can protect children from the negative effects of low peer acceptance throughout the primary school years.

Acknowledgments Open access funding provided by University of Eastern Finland (UEF) including Kuopio University Hospital.

Author's Contribution MZ contributed to this study by working on the conceptualization and writing of the first draft of the manuscript and its revisions. MG conducted the analysis. KA, JN, and NK helped with the conceptualization and writing of the manuscript. ML conducted the data collection. All authors read and have approved the final manuscript.

Funding This work has been Carried out in the Center of MultiLeTe and funded by grants from the Academy of Finland to Authors Jari-Erik Nurmi, Noona Kiuru and Marja-Kristiina Lerkkanen.

Data Availability This manuscript's data will not be deposited. MZ and MG take responsibility for the integrity of the data and the accuracy of the data analysis.

\section{Compliance with Ethical Standards}

Conflict of interest The authors declare that they have no conflict of interest.

Ethical Approval This study involved human participants and all procedures performed were in accordance with the ethical standards and guidelines on research ethics given by University of Jyväskylä, the national research committee and with the 1964 Helsinki declaration and its later amendments or comparable ethical standards.

Informed Consent Informed consent was obtained from all individual participants included in the study.

Open Access This article is distributed under the terms of the Creative Commons Attribution 4.0 International License (http://creativecommons.org/licenses/by/4.0/), which permits unrestricted use, distribution, and reproduction in any medium, provided you give appropriate credit to the original author(s) and the source, provide a link to the Creative Commons license, and indicate if changes were made. 


\section{References}

Arseneault, L. (2017). The long-term impact of bullying victimization on mental health. World Psychiatry, 16, 27-28.

Aunola, K., \& Nurmi, J.-E. (2004). Maternal affection moderates the impact of psychological control on a child's mathematical performance. Developmental Psychology, 40, 965-978. https://doi. org/10.1037/0012-1649.40.6.965.

Aunola, K., \& Nurmi, J. E. (2005). The role of parenting styles in children's problem behavior. Child Development, 76, 1144-1159. https://doi.org/10.1111/j.1467-8624.2005.00840.x-i1.

Aunola, K., Sorkkila, M., Viljaranta, J., Tolvanen, A., \& Ryba, T. V. (2018). The role of parental affection and psychological control in adolescent athletes' symptoms of burnout. Journal of Adolescence, 69, 140-149. https://doi.org/10.1016/j.adolescence.2018.10.001.

Barber, B. K. (1996). Parental psychological control: Revisiting a neglected construct. Child Development, 67, 3296-3319. https://doi.org/10.2307/1131780.

Barber, B. K., Xia, M. (2013). The centrality of control to parenting and its effects. In R. E. Larzelere, A. S. Morris, A. W. Harrist (Eds.), Authoritative parenting. Synthesizing nurturance and discipline for optimal child development (pp. 61-87). Washington, DC: American Psychological Association.

Barrett, P. M., Lock, S., \& Farrell, L. J. (2005). Developmental differences in universal preventive intervention for child anxiety. Clinical Child Psychology and Psychiatry, 10, 539-555. https://doi. org/10.1177/1359104505056317.

Bilsky, S. A., Cole, D. A., Dukewich, T. L., Martin, N. C., Sinclair, K. R., Tran, C. V., et al. (2013). Does supportive parenting mitigate the longitudinal effects of peer victimization on depressive thoughts and symptoms in children. Journal of Abnormal Psychology, 122(2), 406-419. https://doi.org/10.1037/ a0032501.

Bossaert, G., Doumen, S., Buyse, E., \& Verschueren, K. (2011). Predicting children's academic achievement after the transition to first grade: A two-year longitudinal study. Journal of Applied Developmental Psychology, 32, 47-57. https://doi.org/10.1016/j.appdev.2010.12.002.

Bowes, L., Maughan, B., Caspi, A., Moffitt, T. E., \& Arseneault, L. (2010). Families promote emotional and behavioural resilience to bullying: Evidence of an environmental effect. Journal of Child Psychology and Psychiatry, 51, 809-817. https://doi.org/10.1111/j.1469-7610.2010.02216.x.

Buckholdt, K. E., Kitzmann, K. M., \& Cohen, R. (2016). Parent emotion coaching buffers the psychological effects of poor peer relations in the classroom. Journal of Social and Personal Relationships, 33, 23-41. https://doi.org/10.1177/0265407514562560.

Bukowski, W. M. (2001). Friendship and the worlds of childhood. New Directions for Child and Adolescent Development, 91, 93-105. https://doi.org/10.1002/cd.7.

Bukowski, W. M., \& Hoza, B. (1989). Popularity and friendship: Issues in theory, measurement, and outcome. In T. J. Berndt \& G. W. Ladd (Eds.), Peer relationships in child development (pp. 15-45). New York: Wiley.

Bukowski, W. M., Laursen, B., \& Hoza, B. (2010). The snowball effect: Friendship moderates escalations in depressed affect among avoidant and excluded children. Development and Psychopathology, 22, 749757. https://doi.org/10.1017/S095457941000043X.

Burton, E., Stice, E., \& Seeley, J. R. (2004). A prospective test of the stress-buffering model of depression in adolescent girls: No support once again. Journal of Consulting and Clinical Psychology, 72, 689-697. https://doi.org/10.1037/0022-006X.72.4.689.

Campbell, S. B., \& Stauffenberg, C. V. (2007). Child characteristics and family processes that predict behavioral readiness. In A. Booth \& A. C. Crouter (Eds.), Disparities in school readiness: How families contribute to transitions to school (pp. 225-258). Mahwah: Erlbaum.

Cohen, S., \& Wills, T. A. (1985). Stress, social support, and the buffering hypothesis. Psychological Bulletin, 98, 310-357. https://doi.org/10.1037/0033-2909.98.2.310.

Collins, W. A., Laursen, B., Mortensen, N., Luebker, C., \& Ferreira, M. (1997). Conflict processes and transitions in parent and peer relationships: Implications for autonomy and regulation. Journal of Adolescent Research, 12, 178-198. https://doi.org/10.1177/0743554897122003.

Collins, W. A., \& Russell, G. (1991). Mother-child and father-child relationships in middle childhood and adolescence: A developmental analysis. Developmental Review, 11, 99-136. https://doi. org/10.1016/0273-2297(91)90004-8.

Coplan, R. J., \& Arbeau, K. A. (2008). The stresses of a "brave new world": Shyness and school adjustment in kindergarten. Journal of Research in Childhood Education, 22, 377-389. https://doi. org/10.1080/02568540809594634. 
Deci, E. L., \& Ryan, R. M. (2000). The "what" and "why" of goal pursuits: Human needs and the selfdetermination of behavior. Psychological Inquiry, 11, 227-268. https://doi.org/10.1207/S15327965P LI1104_01.

Denham, S. A. (2006). Social-emotional competence as support for school readiness: What is it and how do we assess it? Early Education and Development, 17(1), 57-89. https://doi.org/10.1207/s15566935e ed1701_4.

El-Sheikh, M., Hinnant, J. B., Kelly, R. J., \& Erath, S. (2010). Maternal psychological control and child internalizing symptoms: Vulnerability and protective factors across bioregulatory and ecological domains. Journal of Child Psychology and Psychiatry, 51, 188-198. https://doi.org/10.111 1/j.1469-7610.2009.02140.x.

Fabes, R. A., \& Eisenberg, N. (1992). Young children's coping with interpersonal anger. Child Development, 63, 116-128. https://doi.org/10.2307/1130906.

Forbes, M. K., Fitzpatrick, S., Magson, N. R., \& Rapee, R. M. (2018). Depression, anxiety, and peer victimization: Bidirectional relationships and associated outcomes transitioning from childhood to adolescence. Journal of Youth and Adolescence. https://doi.org/10.1007/s10964-018-0922-6.

Gifford-Smith, M., Dodge, K. A., Dishion, T. J., \& McCord, J. (2005). Peer influence in children and adolescents: Crossing the bridge from developmental to intervention science. Journal of Abnormal Child Psychology, 33, 255-265. https://doi.org/10.1007/s10802-005-3563-7.

Goodman, R. (1997). The strengths and difficulties questionnaire: A research note. Journal of Child Psychology and Psychiatry, 38, 581-586. https://doi.org/10.1111/j.1469-7610.1997.tb01545.x.

Grover, R. L., Ginsburg, G. S., \& Ialongo, N. (2007). Psychosocial outcomes of anxious first graders: A seven-year follow-up. Depression and Anxiety, 24, 410-420. https://doi.org/10.1002/da.20241.

Hale, W. W., Van Der Valk, I., Engels, R., \& Meeus, W. (2005). Does perceived parental rejection make adolescents sad and mad? The association of perceived parental rejection with adolescent depression and aggression. Journal of Adolescent Health, 36, 466-474. https://doi.org/10.1016/j.jadohealth 2004.04.007.

Hart, C. H., Newell, L. D., \& Olsen, S. F. (2003). Parenting skills and social-communicative competence in childhood. In J. O. Greene \& B. R. Burleson (Eds.), Handbook of communication and social interaction skills (pp. 753-797). Mahwah: Erlbaum.

Hazel, N. A., Oppenheimer, C. W., Technow, J. R., Young, J. F., \& Hankin, B. L. (2014). Parent relationship quality buffers against the effect of peer stressors on depressive symptoms from middle childhood to adolescence. Developmental Psychology, 50, 2115-2123. https://doi.org/10.1037/a0037192.

Healy, K. L., \& Sanders, M. R. (2018). Mechanisms through which supportive relationships with parents and peers mitigate victimization, depression and internalizing problems in children bullied by peers. Child Psychiatry and Human Development, 49, 800-813. https://doi.org/10.1007/s10578-018-0793-9.

Healy, K. L., Sanders, M. R., \& Iyer, A. (2015). Facilitative parenting and children's social, emotional and behavioral adjustment. Journal of Child and Family Studies, 24, 1762-1779. https://doi.org/10.1007/ s10826-014-9980-x.

Hoglund, W. L., \& Chisholm, C. A. (2014). Reciprocating risks of peer problems and aggression for children's internalizing problems. Developmental Psychology, 50, 586-599. https://doi.org/10.1037/a0033 617.

Hymel, S., Closson, L. M., Caravita, S., \& Vaillancourt, T. (2011). Social status among peers: From sociometrist attraction to peer acceptance to perceived popularity. In P. K. Smith \& C. H. Hart (Eds.), Handbook of childhood social development (2nd ed., pp. 375-392). Malden, MA: Wiley/Blackwell.

Ialongo, N., Edelsohn, G., Werthamer-Larsson, L., Crockett, L., \& Kellam, S. (1995). The significance of self-reported anxious symptoms in first grade children: Prediction to anxious symptoms and adaptive functioning in fifth grade. Journal of Child Psychology and Psychiatry, 36(3), 427-437. https://doi. org/10.1111/j.1469-7610.1995.tb01300.x.

Jiang, X. L., \& Cillessen, A. H. (2005). Stability of continuous measures of sociometric status: A metaanalysis. Developmental Review, 25, 1-25. https://doi.org/10.1016/j.dr.2004.08.008.

Johnson, D. W. (1980). Group processes: Influences of student-student interaction on school outcomes. Cambridge: Academic Press.

Kiuru, N., Aunola, K., Lerkkanen, M. K., Pakarinen, E., Poskiparta, E., Ahonen, T., et al. (2015). Positive teacher and peer relations combine to predict primary school students' academic skill development. Developmental Psychology, 51, 434-446. https://doi.org/10.1037/a0038911.

Klima, T., \& Repetti, R. L. (2008). Children's peer relations and their psychological adjustment: Differences between close friendships and the larger peer group. Merill-Palmer Quarterly, 54, 151-178. https:// doi.org/10.1353/mpq.2008.0016. 
Ladd, G. W. (2006). Peer rejection, aggressive or withdrawn behavior, and psychological maladjustment from ages 5 to 12: An examination of four predictive models. Child Development, 77, 822-846. https:// doi.org/10.1111/j.1467-8624.2006.00905.x.

Ladd, G. W., \& Price, J. M. (1987). Predicting children's social and school adjustment following the transition from preschool to kindergarten. Child Development, 58, 1168-1189. https://doi.org/10.2307/11306 13.

Ladd, G. W., \& Troop-Gordon, W. (2003). The role of chronic peer difficulties in the development of children's psychological adjustment problems. Child Development, 74, 1344-1367. https://doi. org/10.1111/1467-8624.00611.

Lamb, M. E., \& Oppenheim, D. (1989). Fatherhood and father-child relationships: Five years of research. In S. H. Cath, A. Gurwitt, \& L. Gunsberg (Eds.), Fathers and their families (pp. 11-26). Hillsdale, NJ: Analytic Press Inc.

Lerkkanen, M.-K., Niemi, P., Poikkeus, A.-M., Poskiparta, E., Siekkinen, M., \& Nurmi, J.-E. (2006-2016). The first steps study [Alkuportaat]. Finland: University of Jyväskylä, University of Turku, and University of Eastern Finland.

Lewin, L. M., Davis, B., \& Hops, H. (1999). Childhood social predictors of adolescent antisocial behavior: Gender differences in predictive accuracy and efficacy. Journal of Abnormal Child Psychology, 27, 277-292. https://doi.org/10.1023/A:1022606608840.

London, B., Downey, G., Bonica, C., \& Paltin, I. (2007). Social causes and consequences of rejection sensitivity. Journal of Research on Adolescence, 17, 481-506. https://doi.org/10.111 1/j.1532-7795.2007.00531.x.

Maccoby, E. E. (1998). The two sexes: Growing up apart, coming together. Cambridge, MA: Belknap.

Maunder, R., \& Monks, C. P. (2018). Friendships in middle childhood: Links to peer and school identification, and general self-worth. British Journal of Developmental Psychology. https://doi. org/10.1111/bjdp.12268.

McDonald, K. L., Bowker, J. C., Rubin, K. H., Laursen, B., \& Duchene, M. S. (2010). Interactions between rejection sensitivity and supportive relationships in the prediction of adolescents' internalizing difficulties. Journal of Youth and Adolescence, 39, 563-574. https://doi.org/10.1007/s1096 4-010-9519-4.

McDougall, P., Hymel, S., Vaillancourt, T., \& Mercer, L. (2001). The consequences of childhood peer rejection. In M. R. Leary (Ed.), Interpersonal rejection (pp. 213-247). New York, NY: Oxford University Press.

McGue, M., Elkins, I., Walden, B., \& Iacono, W. G. (2005). Perceptions of the parent-adolescent relationship: A longitudinal investigation. Developmental Psychology, 41, 971-984. https://doi. org/10.1037/0012-1649.41.6.971.

McKee, L., Colletti, C., Rakow, A., Jones, D. J., \& Forehand, R. (2008). Parenting and child externalizing behaviors: Are the associations specific or diffuse? Aggression and Violent Behavior, 13, 201-215. https://doi.org/10.1016/j.avb.2008.03.005.

McLachlan, J., Zimmer-Gembeck, M. J., \& McGregor, L. (2010). Rejection sensitivity in childhood and early adolescence: Peer rejection and protective effects of parents and friends. Journal of Relationships Research, 1, 31-40. https://doi.org/10.1375/jrr.1.1.31.

McNally, S., Eisenberg, N., \& Harris, J. D. (1991). Consistency and change in maternal child-rearing practices andvalues: A longitudinal study. Child Development, 62, 190-198. https://doi. org/10.2307/1130714.

Menting, B., Koot, H., \& van Lier, P. (2015). Peer acceptance and the development of emotional and behavioural problems: Results from a preventive intervention study. International Journal of Behavioral Development, 39, 530-540. https://doi.org/10.1177/0165025414558853.

Nanda, M. M., Kotchick, B. A., \& Grover, R. L. (2012). Parental psychological control and childhood anxiety: The mediating role of perceived lack of control. Journal of Child and Family Studies, 21, 637-645. https://doi.org/10.1007/s10826-011-9516-6.

Niesel, R. \& Griebel, W. (2007). Enhancing the competence of transition systems through co-construction. In A. W. Dunlop \& H. Fabian (Eds); Informing transitions in the early years (pp. 21-32). Maidenhead: Open University.

Parker, J. G., Rubin, K. H., Erath, S., Wojslawowicz, J. C., \& Buskirk, A. (2006). Peer relationships, child development, and adjustment: A developmental psychopathology perspective. In D. Cicchetti \& D. Cohen (Eds.), Developmental psychopathology: Theory and method (Vol. 2, pp. 419-493). New York, NJ: Wiley.

Patterson, C. J., Cohn, D. A., \& Kao, B. T. (1989). Maternal warmth as a protective factor against risks associated with peer rejection among children. Development and Psychopathology, 1, 21-38. https ://doi.org/10.1017/S0954579400000225. 
Pettit, G. S., Bates, J. E., \& Dodge, K. A. (1997). Supportive parenting, ecological context, and children's adjustment: A seven-year longitudinal study. Child Development, 68, 908-923. https://doi. org/10.1111/j.1467-8624.1997.tb01970.x.

Preacher, K. J., Curran, P. J., \& Bauer, D. J. (2006). Computational tools for probing interactions in multiple linear regression, multilevel modeling, and latent curve analysis. Journal of Educational and Behavioral Statistics, 31, 437-448. https://doi.org/10.3102/10769986031004437.

Ranson, E. K., \& Urichuk, L. J. (2008). The effect of parent-child attachment relationships on child biopsychosocial outcomes: A review. Early Child Development and Care, 178, 129-152. https:// doi.org/10.1080/03004430600685282.

Renk, K., Roberts, R., Roddenberry, A., Luick, M., Hillhouse, S., Meehan, C., et al. (2003). Mothers, fathers, gender role, and time parents spend with their children. Sex Roles, 48(7-8), 305-315. https ://doi.org/10.1023/a:1022934412910.

Roberts, G. C., Block, H., \& Block, J. (1984). Continuity and change in parents' child-rearing practices. Child Development, 55, 586-597. https://doi.org/10.2307/1129970.

Rose, A. J., \& Rudolph, K. D. (2006). A review of sex differences in peer relationship processes: Potential trade-offs for the emotional and behavioral development of girls and boys. Psychological Bulletin, 132, 98-131. https://doi.org/10.1037/0033-2909.132.1.98.

Rubin, K. H., Bukowski, W. M., \& Parker, J. G. (2006). Peer interactions, relationships and groups. In W. Damon (Series Ed.) \& N. Eisenberg (Vol. Ed.), The handbook of child psychology (6th ed., pp. 571645). Hoboken, NJ: Wiley.

Sakyi, K. S., Surkan, P. J., Fombonne, E., Chollet, A., \& Melchior, M. (2015). Childhood friendships and psychological difficulties in young adulthood: An 18-year follow-up study. European Child and Adolescent Psychiatry, 24, 815-826. https://doi.org/10.1007/s00787-014-0626-8.

Sentse, M., \& Laird, R. D. (2010). Parent-child relationships and dyadic friendship experiences as predictors of behavior problems in early adolescence. Journal of Clinical Child \& Adolescent Psychology, 39, 873-884. https://doi.org/10.1080/15374416.2010.517160.

Shin, K. M., Cho, S. M., Shin, Y. M., \& Park, K. S. (2016). Effects of early childhood peer relationships on adolescent mental health: A 6-to 8-year follow-up study in South Korea. Psychiatry Investigation, 13, 383-388. https://doi.org/10.4306/pi.2016.13.4.383.

Smith, P. K., Shu, S., \& Madsen, K. (2001). Characteristics of victims of school bullying: Developmental changes in coping strategies and skills. In J. Juvonen \& S. Graham (Eds.), Peer harassment in school: The plight of the vulnerable and victimized (pp. 332-351). London: Guilford Press.

Soenens, B., \& Vansteenkiste, M. (2010). A theoretical upgrade of the concept of parental psychological control: Proposing new insights on the basis of self-determination theory. Developmental Review, 30, 74-99. https://doi.org/10.1016/j.dr.2009.11.001.

Tennant, R. G., Martin, K. K., Rooney, R., Hassan, S., \& Kane, R. T. (2017). Preventing internalizing problems in young children: A randomized controlled trial of the feelings and friends (year 3) program with a motor skills component. Frontiers in psychology, 8, 291. https://doi.org/10.3389/fpsyg.2017.00291.

Terry, R. (2000). Recent advances in measurement theory and the use of sociometric techniques. New Directions for Child and Adolescent Development, 2000(88), 27-53. https://doi.org/10.1002/cd.23220 008805.

Visconti, K. J., \& Troop-Gordon, W. (2010). Prospective relations between children's behavioral responses to peer victimization and their socioemotional adjustment. Journal of Applied Developmental Psychology, 31, 261-272. https://doi.org/10.1016/j.appdev.2010.05.003.

Zarra-Nezhad, M., Aunola, K., Kiuru, N., Mullola, S., \& Moazami-Goodarzi, A. (2015). Parenting styles and children's emotional development during the first grade: The moderating role of child temperament. Journal of Psychology \& Psychotherapy, 5, 206. https://doi.org/10.4172/2161-0487.1000206.

Zarra-Nezhad, M., Kiuru, N., Aunola, K., Zarra-Nezhad, M., Ahonen, T., Poikkeus, A.-M., et al. (2014). Social withdrawal in children moderates the association between parenting styles and the children's own socioemotional development. Journal of Child Psychology and Psychiatry, 55, 1260-1269. https ://doi.org/10.1111/jcpp.12251.

Publisher's Note Springer Nature remains neutral with regard to jurisdictional claims in published maps and institutional affiliations. 


\section{Affiliations}

\section{Maryam Zarra-Nezhad ${ }^{1,2}$ (D) Ali Moazami-Goodarzi ${ }^{1,3} \cdot$ Kaisa Aunola $^{3}$. Jari-Erik Nurmi ${ }^{3}$ - Noona Kiuru ${ }^{3}$ - Marja-Kristiina Lerkkanen ${ }^{2}$}

Ali Moazami-Goodarzi

moazami.ali@gmail.com

Kaisa Aunola

kaisa.aunola@jyu.fi

Jari-Erik Nurmi

jari-erik.nurmi@jyu.fi

Noona Kiuru

noona.h.kiuru@jyu.fi

Marja-Kristiina Lerkkanen

marja-kristiina.lerkkanen@jyu.fi

1 School of Applied Education Science and Teacher Education, University of Eastern Finland, Joensuu, Finland

2 Department of Teacher Education, University of Jyväskylä, Jyväskylä, Finland

3 Department of Psychology, University of Jyväskylä, Jyväskylä, Finland 